\title{
Two polymorphisms (rs699947, rs2010963) in the VEGFA gene and diabetic retinopathy: an updated meta-analysis
}

\author{
Yan Lu', Yirui Ge', Yuhua Shi, Jie Yin and Zhenping Huang ${ }^{*}$
}

\begin{abstract}
Background: The vascular endothelial growth factor (VEGFA) gene has been suggested to play an important role in the pathogenesis of diabetic retinopathy (DR). However, the results have been inconsistent. In this study, we performed a meta-analysis to clarify the associations between VEGFA polymorphisms and DR risk.

Methods: Published literature from PubMed, EMBASE, Web of Science and Google Scholar were retrieved. Pooled odds ratios (ORs) with 95\% confidence intervals (Cls) were calculated using fixed- or random-effects model.

Results: A total of eight studies (1204 cases and 1198 controls) for rs699947 polymorphism and ten studies (1666 cases and 1782 controls) for rs2010963 polymorphism were included in the meta-analysis. The results suggested that rs699947 polymorphism was marginally associated with DR under a homogeneous co-dominant model ( $A A$ vs. $C C: O R=1.69,95 \% \mathrm{Cl}=1.03-2.77, p=0.040$ ) and a dominant model (AA + AC vs. CC: $O R=1.38$, $95 \% \mathrm{Cl}=1.01-1.90, p=0.040$ ), whereas the association between rs2010963 polymorphism and DR was not significant under all genetic models (all $p>0.05$ ). In the subgroup analysis, the effect size for rs699947 polymorphism was only marginally significant among European populations under a dominant model $(\mathrm{OR}=1.47,95 \% \mathrm{Cl}=1.07-2.02$, $p=0.018$ ), but not among East Asians. After exclusion of outliers which were the source of between-study heterogeneity, there was significant association between rs699947 polymorphism and DR under a homogeneous co-dominant model $(\mathrm{OR}=1.64,95 \% \mathrm{Cl}=1.18-2.28, p=0.003)$, even after multiple comparison correction.
\end{abstract}

Conclusions: Our meta-analysis confirmed the significant association between rs699947 polymorphism and DR after exclusion of outliers, and rs2010963 polymorphism might be not associated with DR.

Keywords: The vascular endothelial growth factor gene, Polymorphism, Diabetic retinopathy, Meta-analysis

\section{Background}

Diabetic retinopathy (DR), a micro-vascular complication of diabetes, is a main cause of blindness in adults [1]. It is well established that DR is determined by both genetic and environmental factors. The longer duration of diabetes, poorer control of blood glucose and elevated blood pressure are the major risk factors in the development of DR. However, genetic factors also play important roles in the pathogenesis of DR [2]. It would be useful to identify molecular markers that may help to predict the development of DR at earlier stages of diabetes.

\footnotetext{
* Correspondence: huangzhenping1963@163.com

${ }^{\dagger}$ Equal contributors

Department of Ophthalmology, Jinling Hospital, School of Medicine, Nanjing University, 305 East Zhongshan Road, Nanjing 210002, PR China
}

Vascular endothelial growth factor (VEGFA), an endothelial cellspecific mitogen, has been implicated as a major contributor to the development of DR [3]. VEGFA could induce the earliest changes in DR including leukostasis, blood-retinal barrier breakdown, and macular edema and neovascularization in progression of DR [4]. The VEGFA gene is located on chromosome 6p21.3 and consists of 8 exons. The genetic variants in the VEGFA gene are suggested to influence levels of VEGFA protein expression. To date, many studies have investigated the associations between polymorphisms in the VEGFA gene and DR. $-634 \mathrm{G} / \mathrm{C}(+405 \mathrm{G} / \mathrm{C}$ or rs2010963) polymorphism in the $5^{\prime}$-untranslated region and-2578C/A (-2549I/D (in high linkage disequilibrium with $-2578 \mathrm{C} / \mathrm{A}$ ) or rs699947) polymorphism in the promoter region of the VEGFA

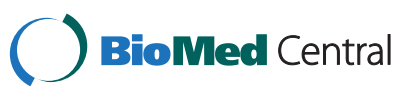

(c) 2013 Lu et al.; licensee BioMed Central Ltd. This is an open access article distributed under the terms of the Creative Commons Attribution License (http://creativecommons.org/licenses/by/2.0), which permits unrestricted use, distribution, and reproduction in any medium, provided the original work is properly cited. 
gene are most frequently investigated. However, the results have been inconsistent [5-16]. To date, three relevant meta-analyses [17-19] have published. However, only two studies for rs699947 polymorphism and five studies for rs2010963 were included in the meta-analysis by Abhary et al. [17]. Only 6 studies for rs2010963 were included in the meta-analysis by Zhao et al. [18]. Although Qiu et al. [19] found the positive association between rs2010963 polymorphism and DR, it should be noted that the association was only marginally significant as $p$ value under allelic model and recessive model was 0.03 . Most importantly, the recent metaanalysis by Qiu et al. [19] omitted two studies [7,16] and included one study [20] where the genotype frequency of rs2010963 polymorphism was not in Hardy-Weinberg Equilibrium (HWE) in controls. Thus, the findings from the meta-analysis by Qiu et al. [19] were inaccurate. Most recently, a number of additional new articles have been published. Therefore, in this study, we performed an updated meta-analysis with 8 studies for rs699947 polymorphism and 10 studies for rs2010963 to further clarify the associations.

\section{Methods}

\section{Literature and search strategy}

We searched PubMed, EMBASE, Web of Science and Google Scholar literature databases. The search strategy to identify all possible studies involved the use of the following key words: (the vascular endothelial growth factor OR VEGFA OR VEGF) and (variant OR variation OR polymorphism OR single nucleotide polymorphism OR SNP) and (diabetic retinopathy OR DR OR PDR). All related studies published in English language were included. The reference lists of retrieved articles were hand-searched. If more than one article were published using the same case series, only the study with the latest data was included. The literature search was updated on July 20, 2013.

\section{Inclusion criteria and data extraction}

The studies included in the meta-analysis met all the following inclusion criteria: (1) evaluated the association of VEGFA polymorphism (rs699947 or rs2010963) with DR; (2) used case-control or cohort design; and (3) provided sufficient data for calculation of odds ratio (OR) with 95\% confidence interval (CI). The following information was extracted from each study: (1) name of the first author; (2) year of publication; (3) origin of country; (4) sample sizes of cases and controls; (5) genotype distributions of cases and controls; and (6) whether the variant was in HWE in controls. Two authors independently searched articles, assessed the articles for compliance with the inclusion/exclusion criteria, resolved disagreements and reached a consistent decision.

\section{Statistical analysis}

The association of VEGFA polymorphism with DR was estimated by calculating pooled ORs and 95\% CIs under a co-dominant, a dominant, and a recessive model, respectively. The significance of pooled OR was determined by $\mathrm{Z}$ test ( $p<0.05$ was considered statistically significant). Q test was performed to evaluate the between-study heterogeneity. A random- (DerSimonian-Laird method [21] or fixed(Mantel-Haenszel method) [22] effects model was used to calculate pooled OR in the presence $(p \leq 0.10)$ or absence $(p>0.10)$ of heterogeneity, respectively. Subgroup analyses by ethnicity and type of DR were performed. Sensitivity analysis was performed after excluding one study at a time to test the stability of the result. Begg's funnel plot, a scatter plot of effect against a measure of study size, was generated as a visual aid to detect bias or systematic heterogeneity [23]. Publication bias was assessed by Egger's test [24] $(p<0.05$ was considered statistically significant). Data analysis was performed using STATA version 11 (StataCorp LP, College Station, TX, USA). In this meta-analysis, we used four genetic models for each of two polymorphisms, and Bonferroni method was used to correct for multiple comparisons $(p=0.05 / 8=0.00625)$.

\section{Results}

\section{Characteristics of the studies}

The literature search identified a total of 162 potentially relevant papers. Of these, 133 papers were excluded because of obvious irrelevance by reading the titles and abstracts. In addition, two reviews $[1,25]$, three metaanalyses [17-19], and three article [26-28] which investigated the association of other polymorphism in the VEGFA gene with DR were excluded. Then, 21 papers met the primary inclusion criteria. However, one duplicated publication [29], four papers [30-33] which provided insufficient data for calculation of OR with $95 \%$ CI were further excluded. In addition, because the variant was not in HWE in controls, one article [15] for rs699947 polymorphism and three articles [20,34,35] for rs2010963 polymorphism were excluded. Additionally, since two studies were included in the article by Abhary et al. [8], they were considered as separate studies in the meta-analysis. At last, a total of 8 studies for rs699947 polymorphism and 10 studies for rs2010963 polymorphism were included in the final meta-analysis. A flow chart describing the study inclusion/ exclusion is displayed as Figure 1. The characteristics of the included studies are listed in Tables 1 and 2 .

\section{Meta-analysis results}

A total of 1204 cases and 1198 controls were identified for the association between rs699947 polymorphism and DR. The results indicated that rs699947 polymorphism was marginally associated with DR under a homogeneous codominant model (AA vs. CC: $\mathrm{OR}=1.69,95 \% \mathrm{CI}=1.03-2.77$, 


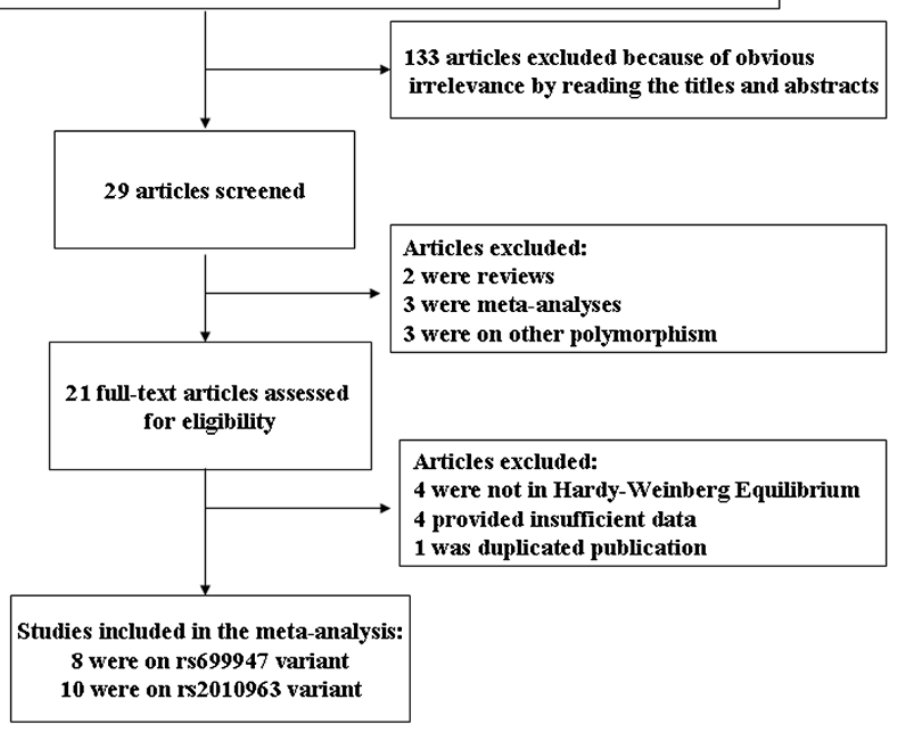

Figure 1 Flow chart of inclusion/exclusion of the individual studies.

$p=0.040$, Figure 2) and a dominant model (AA + AC vs. $\mathrm{CC}: \mathrm{OR}=1.38,95 \% \mathrm{CI}=1.01-1.90, p=0.040)$. Further subgroup analysis suggested that the effect size was only significant among European populations under a dominant model (AA + AC vs. $\mathrm{CC}$ : $\mathrm{OR}=1.47,95 \% \mathrm{CI}=1.07-2.02$, $p=0.018)$, but not among East Asian populations under all genetic models (Table 3). Since only two studies for proliferative DR (PDR) and one study for nonproliferative DR (NPDR) were investigated, the subgroup analysis by type of DR were not performed.

A total of 1666 cases and 1782 controls were identified for the association between rs2010963 polymorphism and DR. The results showed that there was no significant association between this polymorphism and DR under all genetic models (Table 4 and Figure 3), even after stratified for ethnicity and type of DR.

\section{Source of heterogeneity}

Since there was significant between-study heterogeneity for both rs699947 and rs2010963 polymorphisms, we performed a meta-regression analysis to explore source of heterogeneity. We introduced variables including publication year, ethnicity, sample size in cases and controls. However, these variables can not explain the source of heterogeneity. Then, we drew Galbraith figure to further explore the outliers. The pooled results after exclusion of these outliers are listed in Additional file 1: Table S1. The between-study heterogeneity for two polymorphisms disappeared, and non-significant association for rs2010963 polymorphism with DR remained (Additional file 1: Table S1). However, the association between rs699947 polymorphism and DR changed to be significant under homogeneous co-dominant model

Table 1 Characteristic of the studies included in the meta-analysis between rs699947 polymorphism in the VEGFA gene and diabetic retinopathy

\begin{tabular}{|c|c|c|c|c|c|c|c|c|c|c|c|}
\hline \multirow{2}{*}{ Study } & \multirow{2}{*}{ Country } & \multirow{2}{*}{ Ethnicity } & \multicolumn{2}{|c|}{ Sample size } & \multicolumn{3}{|c|}{ Genotype frequency in cases } & \multicolumn{3}{|c|}{ Genotype frequency in controls } & \multirow[b]{2}{*}{$P_{\text {HWE }}$} \\
\hline & & & Cases & $\overline{\text { Controls }}$ & CC & AC & AA & CC & AC & AA & \\
\hline Yang,2003 [5] & UK & European & 64 & 66 & 12 & 31 & 21 & 13 & 38 & 15 & Yes \\
\hline Awata,2005 [6] & Japan & East Asian & 175 & 203 & 95 & 70 & 10 & 93 & 91 & 19 & Yes \\
\hline Buraczynska,2007 [7] & Poland & European & 195 & 91 & 29 & 80 & 86 & 29 & 43 & 19 & Yes \\
\hline Abhary,2009 [8] & Australia & European & 75 & 93 & 17 & 35 & 23 & 26 & 43 & 24 & Yes \\
\hline Abhary,2009 [8] & Australia & European & 136 & 181 & 31 & 74 & 31 & 45 & 91 & 45 & Yes \\
\hline Nakamura,2009 [9] & Japan & East Asian & 177 & 292 & 85 & 70 & 22 & 163 & 107 & 22 & Yes \\
\hline Chun,2010 [10] & Korea & East Asian & 253 & 134 & 123 & 115 & 15 & 92 & 36 & 6 & Yes \\
\hline Yang,2011 [11] & China & East Asian & 129 & 138 & 66 & 47 & 16 & 82 & 51 & 5 & Yes \\
\hline
\end{tabular}


Table 2 Characteristic of the studies included in the meta-analysis between rs2010963 polymorphism in the VEGFA gene and diabetic retinopathy

\begin{tabular}{|c|c|c|c|c|c|c|c|c|c|c|c|}
\hline \multirow{2}{*}{ Study } & \multirow{2}{*}{ Country } & \multirow{2}{*}{ Ethnicity } & \multicolumn{2}{|c|}{ Sample size } & \multicolumn{3}{|c|}{ Genotype frequency in cases } & \multicolumn{3}{|c|}{ Genotype frequency in controls } & \multirow[b]{2}{*}{$P_{\text {HWE }}$} \\
\hline & & & Cases & Controls & GG & GC & $\mathrm{CC}$ & GG & GC & $\mathrm{CC}$ & \\
\hline Awata,2005 [6] & Japan & East Asian & 175 & 200 & 46 & 91 & 38 & 75 & 95 & 30 & Yes \\
\hline Buraczynska,2007 [7] & Poland & European & 195 & 91 & 88 & 88 & 19 & 42 & 41 & 8 & Yes \\
\hline Errera,2007 [12] & Brazil & European & 167 & 334 & 57 & 73 & 37 & 139 & 155 & 40 & Yes \\
\hline Petrovic,2008 [13] & Slovenia & European & 206 & 143 & 79 & 103 & 24 & 61 & 67 & 15 & Yes \\
\hline Uthra,2008 [14] & India & South Asian & 120 & 79 & 60 & 51 & 9 & 44 & 29 & 6 & Yes \\
\hline Nakamura,2009 [9] & Japan & East Asian & 176 & 289 & 63 & 79 & 34 & 84 & 146 & 59 & Yes \\
\hline Kangas-Kontio,2009 [15] & Finland & European & 126 & 96 & 74 & 42 & 10 & 52 & 39 & 5 & Yes \\
\hline Chun,2010 [10] & Korea & East Asian & 253 & 134 & 85 & 125 & 43 & 43 & 69 & 22 & Yes \\
\hline Feghhi,2011 [16] & Iran & European & 119 & 279 & 43 & 49 & 27 & 63 & 139 & 77 & Yes \\
\hline Yang,2011 [11] & China & East Asian & 129 & 137 & 36 & 74 & 19 & 39 & 72 & 26 & Yes \\
\hline
\end{tabular}

$(\mathrm{OR}=1.64,95 \% \mathrm{CI}=1.18-2.28, \quad p=0.003$, Figure 4$)$, even after sensitivity analysis was performed and multiple comparison correction was applied.

\section{Potential publication bias}

Using the Egger's test, no publication bias was detected for the studies on rs699947 polymorphism and rs2010963 polymorphism under all genetic models (all $p>0.05$ ).

\section{Discussion}

The present updated meta-analysis confirmed the significant association between rs699947 polymorphism and DR after exclusion of outliers, and rs2010963 polymorphism might be not associated with DR. In the subgroup analysis, although rs699947 polymorphism was marginally associated with DR among Europeans under a dominant model, it did not reach statistical significance after multiple comparison correction.

To date, a number of studies have investigated association between VEGFA gene variants and risk of DR. Awata et al. [6] first reported that rs2010963 polymorphism was significantly associated with DR in Japanese patients with type 2 diabetes. However, the following studies demonstrated inconsistent results. Another polymorphisms

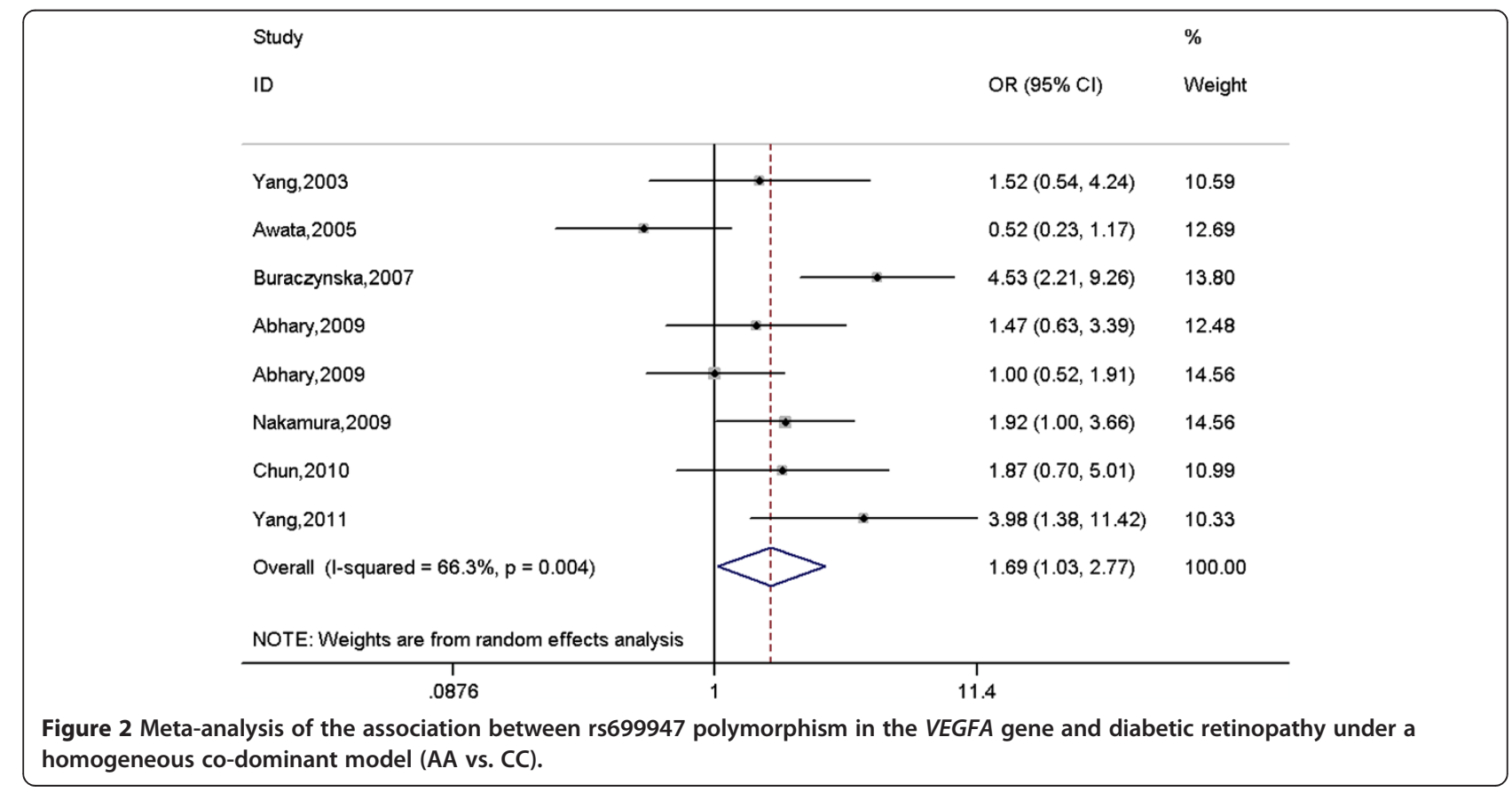


Table 3 Pooled ORs and 95\% Cls of the association between rs699947 polymorphism in the VEGFA gene and diabetic retinopathy

\begin{tabular}{|c|c|c|c|c|c|c|c|c|c|c|c|c|c|c|c|c|c|}
\hline \multirow[t]{2}{*}{ Contrasts } & \multirow{2}{*}{$\begin{array}{l}\text { No. of studies } \\
\text { (cases/controls) }\end{array}$} & \multicolumn{4}{|c|}{$\begin{array}{l}\text { Homogeneous co-dominant model } \\
\text { AA vs. CC }\end{array}$} & \multicolumn{4}{|c|}{$\begin{array}{l}\text { Heterogeneous co-dominant model } \\
\qquad \text { AC vs. CC }\end{array}$} & \multicolumn{4}{|c|}{$\begin{array}{l}\text { Dominant model } \\
\mathrm{AA}+\mathrm{AC} \text { vs. CC }\end{array}$} & \multicolumn{4}{|c|}{$\begin{array}{l}\text { Recessive model } \\
\text { AA vs. AC + CC }\end{array}$} \\
\hline & & OR & $95 \% \mathrm{Cl}$ & $I^{2}(\%)$ & $P_{H}$ & OR & $95 \% \mathrm{Cl}$ & $I^{2}(\%)$ & $P_{\mathrm{H}}$ & OR & $95 \% \mathrm{Cl}$ & $I^{2}(\%)$ & $P_{\mathrm{H}}$ & OR & $95 \% \mathrm{Cl}$ & $I^{2}(\%)$ & $P_{\mathrm{H}}$ \\
\hline All & $8(1204 / 1198)$ & 1.69 & $1.03-2.77^{R}$ & 66.3 & 0.004 & 1.27 & $0.96-1.69^{R}$ & 54.2 & 0.032 & 1.38 & $1.01-1.90^{R}$ & 67.1 & 0.003 & 1.49 & $0.99-2.24^{R}$ & 61.5 & 0.011 \\
\hline \multicolumn{18}{|l|}{ Ethnicity } \\
\hline European & $4(470 / 431)$ & 1.79 & $0.87-3.67^{R}$ & 69.7 & 0.020 & 1.31 & $0.93-1.83^{F}$ & 0.0 & 0.565 & 1.47 & $1.07-2.02^{\mathrm{F}}$ & 46.4 & 0.133 & 1.53 & $0.87-2.68^{R}$ & 68.6 & 0.023 \\
\hline East Asian & $4(734 / 767)$ & 1.59 & $0.71-3.57^{R}$ & 71.7 & 0.014 & 1.26 & $0.79-2.02^{R}$ & 77.3 & 0.004 & 1.33 & $0.82-2.14^{R}$ & 80.3 & 0.002 & 1.46 & $0.72-2.96^{R}$ & 65.1 & 0.035 \\
\hline
\end{tabular}


Table 4 Pooled ORs and 95\% Cls of the association between rs2010963 polymorphism in the VEGFA gene and diabetic retinopathy

\begin{tabular}{|c|c|c|c|c|c|c|c|c|c|c|c|c|c|c|c|c|c|}
\hline \multirow[t]{2}{*}{ Contrasts } & \multirow{2}{*}{$\begin{array}{l}\text { No. of studies } \\
\text { (cases/controls) }\end{array}$} & \multicolumn{4}{|c|}{$\begin{array}{l}\text { Homogeneous co-dominant model } \\
\text { CC vs. GG }\end{array}$} & \multicolumn{4}{|c|}{$\begin{array}{l}\text { Heterogeneous co-dominant model } \\
\text { CG vs. GG }\end{array}$} & \multicolumn{4}{|c|}{$\begin{array}{l}\text { Dominant model } \\
\text { CC + CG vs. GG }\end{array}$} & \multicolumn{4}{|c|}{$\begin{array}{l}\text { Recessive model } \\
\text { CC vs. CG + GG }\end{array}$} \\
\hline & & $\overline{\mathrm{OR}}$ & $95 \% \mathrm{Cl}$ & $I^{2}(\%)$ & $P_{\mathrm{H}}$ & $\overline{\mathrm{OR}}$ & $95 \% \mathrm{Cl}$ & $I^{2}(\%)$ & $P_{\mathrm{H}}$ & OR & $95 \% \mathrm{Cl}$ & $I^{2}(\%)$ & $P_{H}$ & OR & $95 \% \mathrm{Cl}$ & $I^{2}(\%)$ & $P_{\mathrm{H}}$ \\
\hline All & $10(1666 / 1782)$ & 1.11 & $0.80-1.56^{R}$ & 55.6 & 0.016 & 0.98 & $0.80-1.20^{R}$ & 40.6 & 0.087 & 1.01 & $0.81-1.26^{R}$ & 54.4 & 0.020 & 1.13 & $0.93-1.37^{F}$ & 28.1 & 0.186 \\
\hline \multicolumn{18}{|l|}{ Ethnicity } \\
\hline European & $5(813 / 943)$ & 1.17 & $0.64-2.13^{R}$ & 70.0 & 0.010 & 0.90 & $0.66-1.23^{R}$ & 49.5 & 0.094 & 0.95 & $0.67-1.35^{R}$ & 65.0 & 0.022 & 1.25 & $0.81-1.92^{R}$ & 50.6 & 0.088 \\
\hline East Asian & $4(733 / 760)$ & 1.06 & $0.67-1.69^{R}$ & 55.4 & 0.081 & 1.02 & $0.73-1.44^{F}$ & 50.3 & 0.110 & 1.04 & $0.72-1.49^{R}$ & 60.9 & 0.053 & 1.05 & $0.80-1.38^{F}$ & 17.1 & 0.306 \\
\hline South Asian & $1(120 / 79)$ & 1.10 & $0.36-3.32$ & - & - & 1.29 & $0.71-2.35$ & - & - & 1.26 & $0.71-2.22$ & - & - & 0.99 & $0.34-2.89$ & - & - \\
\hline \multicolumn{18}{|l|}{ Type of DR } \\
\hline PDR & $7(924 / 1376)$ & 1.14 & $0.71-1.83^{R}$ & 68.0 & 0.005 & 0.91 & $0.75-1.10^{F}$ & 34.2 & 0.167 & 0.97 & $0.73-1.28^{R}$ & 56.9 & 0.030 & 1.22 & $0.86-1.74^{R}$ & 53.5 & 0.045 \\
\hline NPDR & $3(267 / 331)$ & 1.74 & $0.70-4.29^{R}$ & 62.9 & 0.067 & 1.45 & $0.73-2.87^{R}$ & 70.5 & 0.034 & 1.50 & $0.74-3.03^{R}$ & 74.5 & 0.020 & 1.36 & $0.85-2.18^{F}$ & 0.0 & 0.492 \\
\hline
\end{tabular}

$\mathrm{R}$, random-effect model; $\mathrm{F}$, fixed-effect model. 


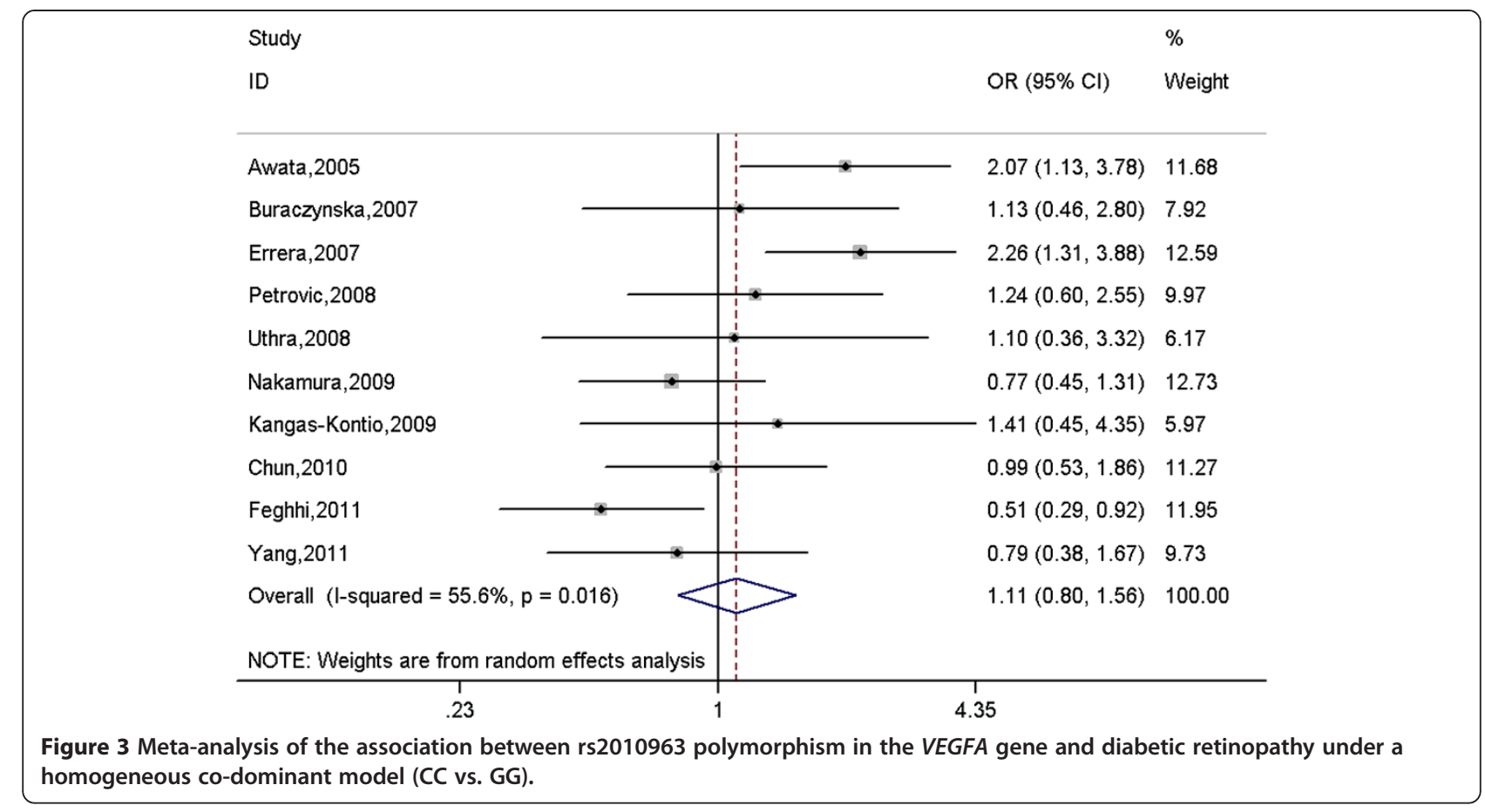

(i.e. rs699947) has also been investigated and the conflicting results were also reported. The discrepant findings might be due to differences in the statistical power, the recruitment of studied population, the type of DR, and the genetic and environmental backgrounds.

In the present meta-analysis, there was evidence of between-study heterogeneity for both rs699947 and rs2010963 polymorphisms. The meta-regression analysis was performed to explore source of heterogeneity.
However, variables such as publication year, ethnicity, sample size in cases and controls can not account for the source heterogeneity. After exclusion of outliers, the heterogeneity for both rs699947 and rs2010963 polymorphisms was abolished. Interestingly, there was significant association between rs699947 polymorphism and DR under a homogeneous co-dominant model $(\mathrm{OR}=1.64,95 \% \mathrm{CI}=1.18-2.28, p=0.003)$, even after multiple comparison correction was applied.

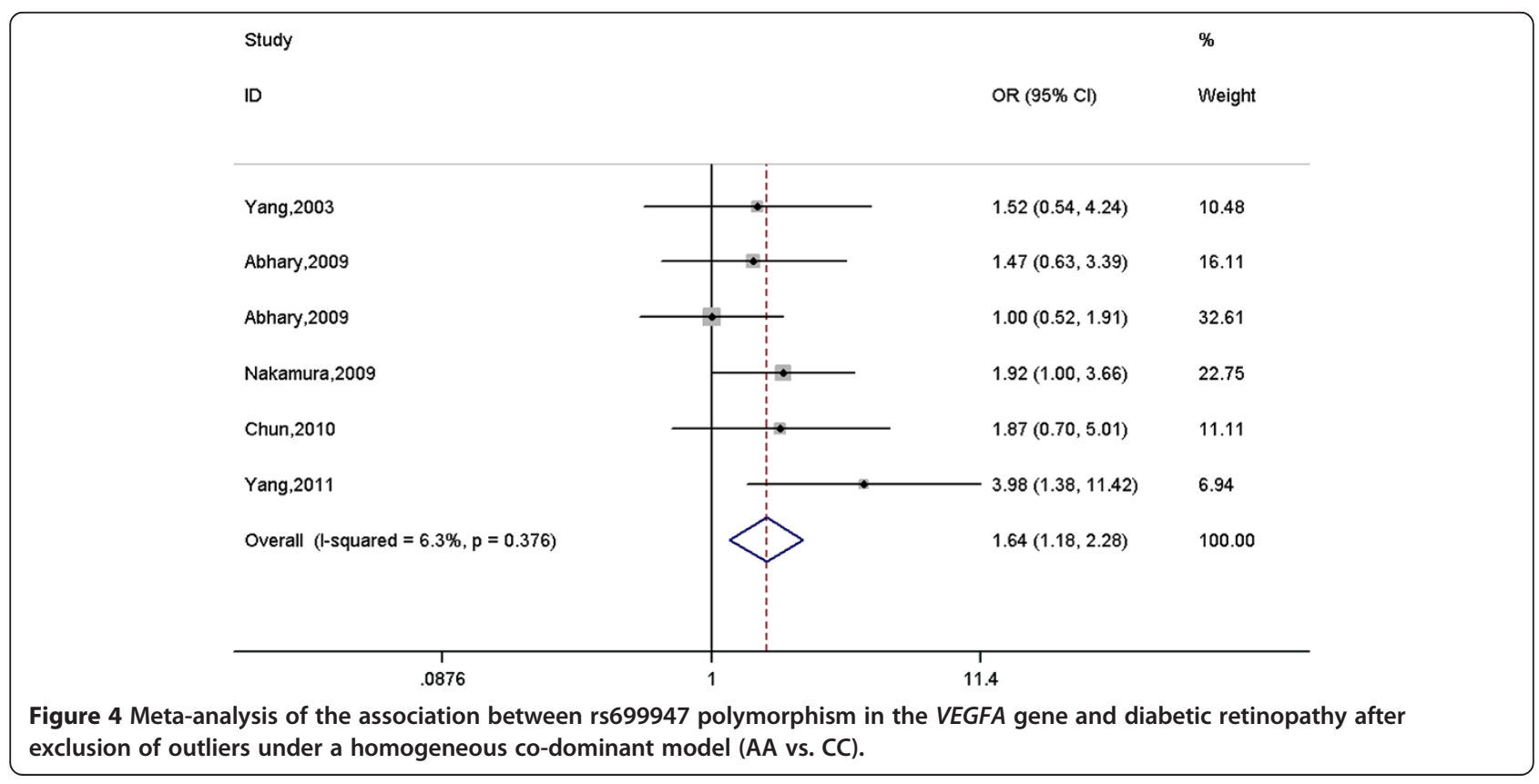


The mechanism between VEGFA gene and DR is currently unclear. DR is characterized by increased vascular permeability, tissue ischemia and neovascularization. VEGFA can stimulate angiogenesis and increases the permeability of the microvasculature [17]. It has been suggested that VEGFA protein expression is affected by genetic variant in the VEGFA gene. Compared with VEGFA levels in the vitreous of diabetic eyes without PDR, those in the vitreous of patients with PDR are significantly elevated [36]. In addition, VEGFA inhibition has been indicated to cause a marked reduction in retinal neovascularization and prevention of the blood-retinal barrier breakdown [4].

Several limitations should be noted. First, the present meta-analysis was based primarily on unadjusted ORs with 95\% CIs and the confounding factors (e.g. age, sex, duration of diabetes and hypertension) were not controlled for. Second, the effects of gene-gene and gene-environment interactions were not addressed in this meta-analysis since the original publications did not provide the related data. Third, the results in the subgroups should be interpreted with caution because of limited sample size. Fourth, for rs699947 polymorphism, since majority of included studies did not report the association with type of DR, we are unable to perform the further analysis. Fifth, we only assessed two polymorphisms in the VEGFA gene, therefore, we can not rule out the possibility that other polymorphisms or haplotypes in this gene might be implicated in the development of DR.

\section{Conclusions}

In conclusions, the results of our meta-analysis indicated that there was a significantly association between VEGFA rs699947 polymorphism and risk of DR after exclusion of outliers, whereas rs2010963 polymorphism might be not associated with risk of DR. Further well-designed large-scale studies with the consideration of gene-gene and gene-environment interactions should be conducted to investigate the association in future.

\section{Additional file}

Additional file 1: Table S1. Pooled ORs and 95\% Cls of the association between VEGFA variants and diabetic retinopathy after exclusion of the outliers.

\section{Competing interests}

The authors declare that they have no competing interests.

\section{Authors' contributions}

Conceived and designed the study: ZH. Acquisition of data: YS JY. Analysis and interpretation of data: $Y L, Y G, Z H$. Drafting the manuscript: $Y L, Y G$. Revising the manuscript critically for important intellectual content: $Y L, Y G$, YS, JY, ZH. All authors read and approved the final manuscript.

\section{Acknowledgements}

This work was supported by Jinling hospital Grant (no.2012019). The funders had no role in study design, data collection and analysis, decision to publish, or preparation of the manuscript.
Received: 9 May 2013 Accepted: 9 October 2013

Published: 16 October 2013

\section{References}

1. Fong DS, Aiello L, Gardner TW, King GL, Blankenship G, Cavallerano JD, et al: Retinopathy in diabetes. Diabetes Care 2004, 271:S84-87.

2. Liew G, Klein R, Wong TY: The role of genetics in susceptibility to diabetic retinopathy. Int Ophthalmol Clin 2009, 49:35-52.

3. Wirostko B, Wong TY, Simo R: Vascular endothelial growth factor and diabetic complications. Prog Retin Eye Res 2008, 27:608-621.

4. Qaum T, Xu Q, Joussen AM, Clemens MW, Qin W, Miyamoto K, et al: VEGF-initiated blood-retinal barrier breakdown in early diabetes. Invest Ophthalmol Vis Sci 2001, 42:2408-2413.

5. Yang B, Cross DF, Ollerenshaw M, Millward BA, Demaine AG: Polymorphisms of the vascular endothelial growth factor and susceptibility to diabetic microvascular complications in patients with type 1 diabetes mellitus. J Diabetes Complications 2003, 17:1-6.

6. Awata T, Kurihara S, Takata N, Neda T, lizuka H, Ohkubo T, et al: Functional VEGF C-634G polymorphism is associated with development of diabetic macular edema and correlated with macular retinal thickness in type 2 diabetes. Biochem Biophys Res Commun 2005, 333:679-685.

7. Buraczynska M, Ksiazek P, Baranowicz-Gaszczyk I, Jozwiak L: Association of the VEGF gene polymorphism with diabetic retinopathy in type 2 diabetes patients. Nephrol Dial Transplant 2007, 22:827-832.

8. Abhary S, Burdon KP, Gupta A, Lake S, Selva D, Petrovsky N, et al: Common sequence variation in the VEGFA gene predicts risk of diabetic retinopathy. Invest Ophthalmol Vis Sci 2009, 50:5552-5558.

9. Nakamura S, Iwasaki N, Funatsu H, Kitano S, Iwamoto Y: Impact of variants in the VEGF gene on progression of proliferative diabetic retinopathy. Graefes Arch Clin Exp Ophthalmol 2009, 247:21-26.

10. Chun MY, Hwang HS, Cho HY, Chun HJ, Woo JT, Lee KW, et al: Association of vascular endothelial growth factor polymorphisms with nonproliferative and proliferative diabetic retinopathy. J Clin Endocrinol Metab 2010, 95:3547-3551.

11. Yang X, Deng Y, Gu H, Lim A, Altankhuyag A, Jia W, et al: Polymorphisms in the vascular endothelial growth factor gene and the risk of diabetic retinopathy in Chinese patients with type 2 diabetes. Mol Vis 2011, 17:3088-3096.

12. Errera Fl, Canani LH, Silva ME, Yeh E, Takahashi W, Santos KG, et al: Functional vascular endothelial growth factor $-634 \mathrm{G}>$ C SNP is associated with proliferative diabetic retinopathy: a case-control study in a Brazilian population of European ancestry. Diabetes Care 2007, 30:275-279.

13. Petrovic MG, Korosec P, Kosnik M, Osredkar J, Hawlina M, Peterlin B, et al: Local and genetic determinants of vascular endothelial growth factor expression in advanced proliferative diabetic retinopathy. Mol Vis 2008, 14:1382-1387.

14. Uthra S, Raman R, Mukesh BN, Rajkumar SA, Padmaja KR, Paul PG, et al: Association of VEGF gene polymorphisms with diabetic retinopathy in a south Indian cohort. Ophthalmic Genet 2008, 29:11-15.

15. Kangas-Kontio T, Vavuli S, Kakko SJ, Penna J, Savolainen ER, Savolainen MJ, et al: Polymorphism of the manganese superoxide dismutase gene but not of vascular endothelial growth factor gene is a risk factor for diabetic retinopathy. $\mathrm{Br} J$ Ophthalmol 2009, 93:1401-1406.

16. Feghhi M, Nikzamir A, Esteghamati A, Mahmoudi T, Yekaninejad MS: Relationship of vascular endothelial growth factor (VEGF) $+405 \mathrm{G} / \mathrm{C}$ polymorphism and proliferative retinopathy in patients with type 2 diabetes. Trans/ Res 2011, 158:85-91.

17. Abhary S, Hewitt AW, Burdon KP, Craig JE: A systematic meta-analysis of genetic association studies for diabetic retinopathy. Diabetes 2009, 58:2137-2147.

18. Zhao T, Zhao J: Association between the $-634 \mathrm{C} / \mathrm{G}$ polymorphisms of the vascular endothelial growth factor and retinopathy in type 2 diabetes: a meta-analysis. Diabetes Res Clin Pract 2010, 90:45-53.

19. Qiu M, Xiong W, Liao H, Li F: VEGF -634G > C polymorphism and diabetic retinopathy risk: a meta-analysis. Gene 2013, 518:310-315.

20. Yang Y, Andresen BT, Yang K, Zhang Y, Li X, Li X, et al: Association of vascular endothelial growth factor $-634 \mathrm{C} / \mathrm{G}$ polymorphism and diabetic retinopathy in type 2 diabetic Han Chinese. Exp Biol Med (Maywood) 2010, 235:1204-1211.

21. DerSimonian R, Laird N: Meta-analysis in clinical trials. Control Clin Trials 1986, 7:177-188.

22. Mantel N, Haenszel W: Statistical aspects of the analysis of data from retrospective studies of disease. J Natl Cancer Inst 1959, 22:719-748. 
23. Begg $C B$, Mazumdar $M$ : Operating characteristics of a rank correlation test for publication bias. Biometrics 1994, 50:1088-1101.

24. Egger M, Davey Smith G, Schneider M, Minder C: Bias in meta-analysis detected by a simple, graphical test. BMJ 1997, 315:629-634.

25. Arden GB, Sivaprasad S: The pathogenesis of early retinal changes of diabetic retinopathy. Doc Ophthalmol 2012, 124:15-26.

26. Kim HW, Ko GJ, Kang YS, Lee MH, Song HK, Kim HK, et al: Role of the VEGF $936 \mathrm{C} / \mathrm{T}$ polymorphism in diabetic microvascular complications in type 2 diabetic patients. Nephrology (Carlton) 2009, 14:681-688.

27. Paine SK, Basu A, Mondal LK, Sen A, Choudhuri S, Chowdhury IH, et al: Association of vascular endothelial growth factor, transforming growth factor beta, and interferon gamma gene polymorphisms with proliferative diabetic retinopathy in patients with type 2 diabetes. Mol Vis 2012, 18:2749-2757.

28. Bonnefond A, Saulnier PJ, Stathopoulou MG, Grarup N, Ndiaye NC, Roussel $R$, et al: What is the contribution of two genetic variants regulating VEGF levels to type 2 diabetes risk and to microvascular complications? PLoS One 2013, 8:e55921.

29. Awata $T$, Inoue K, Kurihara S, Ohkubo T, Watanabe M, Inukai K, et al: A common polymorphism in the $5^{\prime}$-untranslated region of the VEGF gene is associated with diabetic retinopathy in type 2 diabetes. Diabetes 2002, 51:1635-1639.

30. Nakanishi K, Watanabe C: Single nucleotide polymorphisms of vascular endothelial growth factor gene intron 2 are markers for early progression of diabetic retinopathy in Japanese with type 1 diabetes. Clin Chim Acta 2009, 402:171-175.

31. Churchill AJ, Carter JG, Ramsden C, Turner SJ, Yeung A, Brenchley PE, et al: VEGF polymorphisms are associated with severity of diabetic retinopathy. Invest Ophthalmol Vis Sci 2008, 49:3611-3616.

32. Al-Kateb H, Mirea L, Xie X, Sun L, Liu M, Chen H, et al: Multiple variants in vascular endothelial growth factor (VEGFA) are risk factors for time to severe retinopathy in type 1 diabetes: the DCCT/EDIC genetics study. Diabetes 2007, 56:2161-2168.

33. Ray D, Mishra M, Ralph S, Read I, Davies R, Brenchley P: Association of the VEGF gene with proliferative diabetic retinopathy but not proteinuria in diabetes. Diabetes 2004, 53:861-864.

34. Suganthalakshmi B, Anand R, Kim R, Mahalakshmi R, Karthikprakash S, Namperumalsamy $P$, et al: Association of VEGF and eNOS gene polymorphisms in type 2 diabetic retinopathy. Mol Vis 2006, 12:336-341.

35. Szaflik JP, Wysocki T, Kowalski M, Majsterek I, Borucka Al, Blasiak J, et al: An association between vascular endothelial growth factor gene promoter polymorphisms and diabetic retinopathy. Graefes Arch Clin Exp Ophthalmol 2008, 246:39-43.

36. Katsura Y, Okano T, Matsuno K, Osako M, Kure M, Watanabe T, et al: Erythropoietin is highly elevated in vitreous fluid of patients with proliferative diabetic retinopathy. Diabetes Care 2005, 28:2252-2254.

doi:10.1186/1471-2415-13-56

Cite this article as: Lu et al:: Two polymorphisms (rs699947, rs2010963) in the VEGFA gene and diabetic retinopathy: an updated meta-analysis. BMC Ophthalmology 2013 13:56.

\section{Submit your next manuscript to BioMed Central and take full advantage of:}

- Convenient online submission

- Thorough peer review

- No space constraints or color figure charges

- Immediate publication on acceptance

- Inclusion in PubMed, CAS, Scopus and Google Scholar

- Research which is freely available for redistribution

Submit your manuscript at www.biomedcentral.com/submit
C BioMed Central 